\title{
Genetic effects on growth and egg production traits in two-way crosses of Egyptian and commercial layer chickens
}

\author{
W.S. El-Tahawy \& W.S. Habashy \\ Department of Animal and Poultry Production, Faculty of Agriculture, Damanhour University, Damanhour, Egypt
}

(Received 1 February 2021; Accepted 16 March 2021; Published 19 May 2021)

\begin{abstract}
Copyright resides with the authors in terms of the Creative Commons Attribution 4.0 South African Licence.
See: http://creativecommons.org/licenses/by/4.0/za

Condition of use: The user may copy, distribute, transmit and adapt the work, but must recognise the authors and the South African Journal of Animal Science.
\end{abstract}

\begin{abstract}
A crossbreeding experiment was conducted between the Sinai (SI), an indigenous Egyptian strain, and the exotic Lohmann Brown (LB) breeds of chickens. A total of 790 chicks were produced in four genetic groups, namely SI $\times$ SI, LB $\times$ LB, SI $\times$ LB, and LB $\times$ SI. The objective was to estimate the direct additive effect $\left(g^{i}\right)$, individual heterosis $\left(h^{i}\right)$, and maternal additive effect $\left(g^{m}\right)$ for growth and reproduction traits. Direct additive effects were positive $(P \leq 0.01)$ for bodyweight (BW) at 4,8 , and 12 weeks old in favour of SI. For egg production traits, $g^{i}$ was positive for age at sexual maturity (ASM) and age at which the first 10 eggs were produced (P10), but negative for mean 10 egg production (MP10), egg number at 90 days (EN90), mean egg number at 90 days (MEN90), and egg mass (EM). The estimates of heterosis (\%) were high for BW and daily gain except for BW0. Maternal effect estimates of BW and daily weight gain were significant $(P<0.05)$ only for bodyweight at hatching (BW0), bodyweight at 4 weeks old (BW4) and daily weight gain from four to eight weeks old (DWG4-8). Thus, the Sinai and Lohmann Brown crossbreed produced favourable heterosis on the growth of the chicks. As an adapted indigenous strain, SI should be regarded as a dam line in crossing with LB, which has greater genetic potential for growth. Use of LB as a sire strain in conjunction with Sinai would increase egg production from the resulting hybrid chickens.
\end{abstract}

Keywords: crossing, direct effect, Egyptian Sinai, heterosis, Lohmann Brown, maternal effect

${ }^{\#}$ Corresponding Author:Walidh55@gmail.com; Walid.habashi@agr.dmu.edu.eg

\section{Introduction}

Crossbreeding is widely used in poultry breeding programmes because it increases the numbers of heterozygous loci and results in heterosis for traits such as growth and egg production (Amuzu-Aweh et al., 2015). Positive heterosis or hybrid vigour is a phenomenon according to which crossbred offspring exhibit better performance than the average of the parental breeds because the interaction of alleles from the sire and dam results in effects of dominance and epistasis (Fairfull et al.,1985, 1987). But heterosis from epistatic effects is unlikely to be predictable owing to the numerous unknown interactions among loci (Iraqi et al., 2005).

Indigenous chickens have desirable traits such as disease resistance, pleasantly flavoured meat and eggs, and the ability to withstand adverse environmental conditions (Ramadan et al., 2011; Padhi, 2016). Crossing indigenous strains with exotic commercial ones could take advantage of high egg production in the exotic strain and the adaptation of the indigenous strain to the Egyptian environment. Crossbreds that result from the best performing parental breeds could lead to the production of birds that were superior in growth and egg production in a tropical environment. In addition, hybrid vigour could be used to develop new hybrid strains of chickens. Currently, efforts are being made in Egypt to improve the egg production of native chickens through crossbreeding (Saadey et al., 2008; Iraqi et al., 2012; El-Tahawy, 2020). The SI is a mongrel fowl that is raised in the Sinai peninsula desert and is adapted to the hot climate (Soltan et al., 2018). It could be included in crossbreeding programmes to improve the performance of the local chicken population (El-Tahawy, 2020). Lohmann Brown is a composite breed of commercial chicken, developed in Germany, and noted for egg quality, production efficiency and adaptability.

Therefore, the objectives of this study were to evaluate indigenous SI chickens crossed with the LB strain and to estimate the genetic effects on egg production and growth traits. 


\section{Materials and Methods}

All experimental procedures were approved by Animal and Poultry Production Scientific and Ethics Committee, Faculty of Agriculture, Damanhour University, Egypt. The handling and care of the animals were performed so as to maintaini their rights, ensure their welfare, and cause minimal stress, according to International Guidelines for research involving animals (Directive 2010/63/EU). The study was carried out at the Poultry research unit (EL-Bostan farm) Department of Animal and Poultry Production, Faculty of Agriculture, Damanhour University. Indigenous SI and LB strains were used and pullets of each strain were assigned to two groups. The first group mated with eight cocks from the same strain, whereas the second group was mated with cocks from the other strain. Eggs from the four mating groups were collected from each breeding pen and incubated at $37.6{ }^{\circ} \mathrm{C}$ with relative humidity of $55 \%$ during the first 18 days of incubation. Eggs were turned automatically every hour. Ventilation channels were opened and closed automatically according to temperature fluctuation. The ventilator was limited to 0.5 to 3.0 ventilation units until the 18th day of incubation and then to 1.5 to 4.0 units. Incubated eggs were transferred on day 18 to hatchers at $37.1^{\circ} \mathrm{C}$ with relative humidity of $70 \%$. Three hatchers were used to produce the birds for this study. At hatching, all chicks were wing banded according to genetic group and distributed to floor brooders at a starting temperature of $32{ }^{\circ} \mathrm{C}$ for the first week, which was then decreased by $3^{\circ} \mathrm{C}$ each week. All birds were housed in the same room and had the same management and environmental conditions throughout the experiment. All birds were fed ad libitum with a commercial diet containing $21 \%$ crude protein and $2.9 \mathrm{Kcal}$ metabolizable energy $/ \mathrm{kg}$ up to 7 weeks old. Then they received a diet containing $18 \%$ crude protein and 2.8 $\mathrm{kcal}$ metabolizable energy $/ \mathrm{kg}$ feed until 18 weeks old. At 18 weeks old pullets were moved to individual laying cages $(20 \times 45 \times 40 \mathrm{~cm}$ ). During egg production, hens received a diet containing $16 \%$ crude protein and $2.75 \mathrm{kcal}$ metabolizable energy $/ \mathrm{kg}$ feed, $3.5 \%$ calcium and $0.5 \%$ available phosphorus. Light intensity was provided for 16 hours per day during the laying period. The numbers of sires and dams and their purebred or crossbred progeny are shown in Table 1.

Table 1 Groups of Sinai and Lohmann Brown chicks, numbers of purebred and crossbred progeny, and numbers of sires and dams used in their production

\begin{tabular}{lccccc}
\hline Genetic group of chicks & N of chicks & $\begin{array}{c}\text { Genetic group } \\
\text { of sires }\end{array}$ & N of sires & $\begin{array}{c}\text { Genetic group } \\
\text { of dams }\end{array}$ & N of dams \\
\hline Sinai (SI) & 294 & SI & 8 & SI & 59 \\
Lohmann Brown (LB) & 156 & LB & 8 & LB & 49 \\
SI x LB & 139 & SI & 8 & LB & 43 \\
LB x SI & 201 & LB & 8 & SI & 52 \\
Total & 790 & & 32 & & 203 \\
\hline
\end{tabular}

Bodyweight was recorded to the nearest $0.1 \mathrm{~g}$ at hatching (BW0), at four weeks old (BW4), eight weeks old (BW8) and 12 weeks old (BW12). Bodyweight gain was estimated from 4 to 8 weeks, 8 to 12 weeks and from 4 to 12 weeks. Age at the first egg laid or sexual maturity (ASM) was defined as the number of days from hatching to the first laid egg. For each hen, the duration of laying the first 10 eggs (P10) and their weight (EW10) were recorded, as were the number of eggs laid during the 90-day laying period (N90) and the average weight of the eggs produced through 90 days of laying (EW90). Egg mass (EM) was calculated for each hen.

The data were analysed with the GLM procedure of SAS (SAS Institute Inc., Cary, North Carolina, USA). Individual bodyweights and bodyweight gain were analysed with the linear model:

$$
y_{i j k}=\mu+G_{i}+H_{j}+G H_{i j}+e_{i j k}
$$

where: $y_{i j k}=$ an observation on chicken $\mathrm{ijk}, \mu=$ the overall mean, $G_{i}=$ the fixed effect of the ith genetic group, $H_{j}=$ the fixed effect of the jth hatch, $G H_{i j}=$ the interaction of the ith genetic group with the jth hatch, and $e_{i j k}=$ random residual error. Direct and maternal additive effects on growth and egg production traits were estimated using a set of linear contrasts of the genetic group means (Dickerson, 1993).

$$
\text { Direct additive effect: } g^{i}=0.5 x((S I x S I)+(S I x L B)-(L B x L B)-(L B x S I))
$$




$$
\begin{aligned}
\text { Maternal additive effect: } g^{m} & =(S I x L B)-(L B x S I) \\
\text { Individual heterosis: } h^{i} & =\frac{0.5(S I x L B+L B x S I)}{0.5(S I+L B)}
\end{aligned}
$$

\section{Results and Discussion}

Means, standard deviations (SD), and coefficients of variation (CV) expressed as a percentage for the growth and egg production traits are summarized in Table 2.

\begin{tabular}{|c|c|c|c|}
\hline Trait & Mean & SD & CV \\
\hline \multicolumn{4}{|l|}{ Body weight (g) } \\
\hline At hatching & 36.1 & 2.7 & 7.4 \\
\hline 4 weeks & 232.8 & 57.3 & 24.6 \\
\hline 8 weeks & 581.7 & 112.8 & 19.4 \\
\hline 12 weeks & 918.5 & 188.3 & 20.5 \\
\hline \multicolumn{4}{|l|}{ Bodyweight gain $(g / d)$} \\
\hline 4 - 8 weeks & 12.5 & 3.6 & 29.2 \\
\hline $8-12$ weeks & 12.0 & 5.1 & 42.6 \\
\hline $4-12$ weeks & 12.2 & 3.2 & 26.1 \\
\hline \multicolumn{4}{|l|}{ Egg production trait } \\
\hline Age at first egg, days & 149.7 & 11.9 & 8.0 \\
\hline Time to produce the first 10 eggs, days & 15.1 & 3.9 & 25.9 \\
\hline Average weight of the first 10 eggs, $g$ & 46.1 & 6.0 & 13.1 \\
\hline Number of eggs produced in 90 days & 50.2 & 14.9 & 29.7 \\
\hline Average weight of eggs produced in 90 days, $g$ & 51.6 & 7.9 & 15.3 \\
\hline Egg mass, $g$ & 2634.0 & 1066.2 & 40.5 \\
\hline
\end{tabular}

Table 2 Descriptive statistics for bodyweight, bodyweight gain and egg production traits

Lohmann Brown birds were heavier at hatching $(P<0.0001)$, but the more rapid growth of the $\mathrm{SI}$ chickens from 4 to 8,8 to 12 , and 4 to 12 weeks old produced the observed differences in BW at later ages $(P<0.0001)$. Least square means of BW at various ages of the four genetic groups are shown in Table 3.

Table 3 Least squares means ( \pm SE) for bodyweight and daily weight gain of indigenous Sinai, Lohmann

\begin{tabular}{|c|c|c|c|c|c|}
\hline \multirow{2}{*}{ Trait } & \multicolumn{4}{|c|}{ Genetic group } & \multirow{2}{*}{$P$-value } \\
\hline & Sinai $(S I)$ & Lohmann Brown (LB) & LB $\times S I$ & SI $x$ LB & \\
\hline Number & 294 & 156 & 201 & 139 & $<0.0001$ \\
\hline \multicolumn{6}{|l|}{ Body weight, g } \\
\hline At hatch & $35.8 \pm 0.2$ & $36.7 \pm 0.2$ & $35.7 \pm 0.2$ & $36.6 \pm 0.2$ & $<0.0001$ \\
\hline 4 weeks & $225.6 \pm 2.7$ & $203.3 \pm 2.3$ & $243.8 \pm 3.7$ & $265.2 \pm 7.0$ & $<0.0001$ \\
\hline 8 weeks & $586.6 \pm 6.4$ & $505.1 \pm 6.6$ & $615.2 \pm 7.5$ & $609.1 \pm 10.2$ & $<0.0001$ \\
\hline 12 weeks & $925.6 \pm 9.8$ & $757.5 \pm 7.7$ & $983.8 \pm 13.9$ & $989.7 \pm 15.9$ & $<0.0001$ \\
\hline \multicolumn{6}{|c|}{ Average daily gain, $\mathrm{g} / \mathrm{d}$} \\
\hline Weeks 4 to 8 & $12.89 \pm 0.20$ & $10.78 \pm 0.28$ & $13.26 \pm 0.24$ & $12.28 \pm 0.29$ & $<0.0001$ \\
\hline Weeks 8 to 12 & $12.10 \pm 0.28$ & $9.01 \pm 0.39$ & $13.16 \pm 0.34$ & $13.59 \pm 0.41$ & $<0.0001$ \\
\hline Weeks 4 to 12 & $12.50 \pm 0.17$ & $9.89 \pm 0.23$ & $13.21 \pm 0.21$ & $12.93 \pm 0.25$ & $<0.0001$ \\
\hline
\end{tabular}
Brown chickens and their reciprocal crosses 
The LB chickens produced the first egg at a younger age, generated 10 eggs more quickly, produced more eggs in the 90-day laying period, and had heavier eggs than the SI chickens (Table 4). Previous studies likewise reported significant differences in the performance of SI and LB strains of chickens (Iraqi et al., 2003; Lalev et al., 2014 ; Soliman et al., 2020; El-Tahawy, 2020).

Table 4 Least squares means $( \pm$ SE) for egg production traits of indigenous Sinai, Lohmann Brown chickens and their reciprocal crosses

\begin{tabular}{|c|c|c|c|c|c|}
\hline \multirow{2}{*}{ Trait } & \multicolumn{4}{|c|}{ Genetic group } & \multirow{2}{*}{$P$-value } \\
\hline & Sinai $(S I)$ & Lohmann Brown (LB) & LB x SI & SI x LB & \\
\hline Number & 294 & 156 & 201 & 139 & $<0.0001$ \\
\hline ASM, days & $154.56 \pm 0.82$ & $144.94 \pm 0.91$ & $148.21 \pm 1.04$ & $149.51 \pm 1.13$ & $<0.0001$ \\
\hline P10, days & $16.05 \pm 0.27$ & $13.89 \pm 0.31$ & $15.51 \pm 0.35$ & $14.83 \pm 0.38$ & $<0.0001$ \\
\hline EW10, g & $42.54 \pm 0.37$ & $50.41 \pm 0.42$ & $45.56 \pm 0.48$ & $46.86 \pm 0.52$ & $<0.0001$ \\
\hline N90 & $41.56 \pm 0.92$ & $61.26 \pm 1.02$ & $49.72 \pm 1.18$ & $50.12 \pm 1.28$ & $<0.0001$ \\
\hline EW90, g & $47.06 \pm 0.51$ & $56.45 \pm 0.55$ & $53.44 \pm 0.64$ & $50.71 \pm 0.70$ & $<0.0001$ \\
\hline EM, g & $1960.90 \pm 64.08$ & $3494.86 \pm 70.72$ & $2562.77 \pm 81.66$ & $2653.6 \pm 88.77$ & $<0.0001$ \\
\hline
\end{tabular}

ASM: age at first egg, P10: time to produce the first 10 eggs, EW10: average weight of the first 10 eggs, N90: number of eggs produced in 90 days, EW90: average weight of eggs produced in 90 days, EM: egg mass, $g$

A pureline difference measures the difference in the sums of direct and maternal additive effects for SI and LB chickens. The pureline difference ranged from $0.21 \%$ to $20.69 \%$ for bodyweight and $9.46 \%$ to $33.35 \%$ for daily gain, respectively. The $g^{i}$ effects was positive $(P \leq 0.001)$ for bodyweight at 4,8 and 12 weeks old, indicating the greater genetic potential for growth of the SI chicken genotype compared with that of the LB. Other studies reported positive direct additive effects that ranged from $2.22 \%$ to $15.23 \%$ for growth and from 3.5\% to 14.6\% for daily gain (Khalil et al., 1999; Iraqi et al., 2013; Lalev et al., 2014). In a study that crossed Fayoumi and Rhode Island Red chickens, Saleh et al. (2020) reported that the percentage of direct additive effect, relative to the pureline mean, ranged from $1.8 \%$ to $9.2 \%$ for bodyweight and from $4.2 \%$ to $17.3 \%$ for daily gain. Comparable estimates from this study indicate the relative magnitude of the direct additive effects on growth traits to average $9.9 \%$. Estimates of the genetic effects on growth and egg production traits are shown in Table 5.

The $\mathrm{g}^{\mathrm{i}}$ effects on ASM and P10 were positive, indicating the additive genetic potential for earlier sexual maturity and greater rate of egg production by the LB genotype. Direct additive effects on the measures of egg weight and rate of lay also favoured the LB genotype (Table 5). Therefore, LB sired chickens could be used as breeding stock to improve these traits.

Maternal additive effects were not different from zero for all traits except BW0, BW4, the rate of gain from hatching to four weeks and average egg weight over the 90-day laying period (Table 5). Chicks from LB dams had favourable growth early in life compared with those from SI dams, which was consistent with the results reported by Soliman et al. (2020). The hens had no direct contact with their chicks after hatching, which might reflect an in ovo difference between the strains. Also because the hens were separated from their eggs prior to hatching the lack of significant maternal genetic effects is not surprising. Iraqi (2008) and Razuki and Al-Shaheen (2011) also found a lack of maternal effects on egg production and egg weight.

Estimates of $h^{i}$ were significantly positive for BW and daily gain except at hatching. The variability in the estimates of percentage of direct heterosis relative to the mean of the purelines supports the reports by Lamont and Deeb (2001) and El-Tahawy (2020) that the hybrid vigour for bodyweight depends on age. Several other reports demonstrated that bodyweights of crossbred chickens displayed positive hybrid vigour at different ages (Khalil et al., 1999; Sabri et al., 2000; Iraqi et al., 2013). For daily gain, estimates of $h^{i}$ varied from $0.94 \mathrm{~g} / \mathrm{d}$ to $2.82 \mathrm{~g} / \mathrm{d}$. 
Table 5 Genetic effects on bodyweight, daily weight gain and egg production traits in crossing Sinai and Lohmann Brown chickens

\begin{tabular}{|c|c|c|c|c|c|}
\hline Trait & $\begin{array}{l}\text { Pure line } \\
\text { difference }\end{array}$ & $\begin{array}{c}\text { Direct additive } \\
\text { effect }\end{array}$ & $\begin{array}{c}\text { Maternal additive } \\
\text { effect }\end{array}$ & Heterosis & Heterosis $\%$ \\
\hline \multicolumn{6}{|l|}{ Bodyweight, g } \\
\hline At hatch & $-0.98 \pm 0.26^{\star * *}$ & $0.08 \pm 0.39^{\mathrm{ns}}$ & $-0.91 \pm 0.29^{* * *}$ & $-0.10 \pm 0.39^{\mathrm{ns}}$ & -0.28 \\
\hline Week 4 & $22.32 \pm 5.32^{\star \star \star}$ & $21.85 \pm 3.98^{\star \star \star}$ & $-21.39 \pm 5.92^{\star *}$ & $50.05 \pm 3.98^{* *}$ & 23.34 \\
\hline Week 8 & $81.44 \pm 10.47^{\star \star \star}$ & $37.70 \pm 7.84^{* \star *}$ & $6.10 \pm .66^{\mathrm{ns}}$ & $66.30 \pm 7.84^{\star \star \star}$ & 12.15 \\
\hline Week 12 & $168.14 \pm 26.35^{\star \star *}$ & $87.00 \pm 12.50^{* * *}$ & $-5.99 \pm 18.60^{\mathrm{ns}}$ & $145.2 \pm 12.50^{* * *}$ & 17.25 \\
\hline \multicolumn{6}{|c|}{ Daily weight gain, g/d } \\
\hline Weeks 4 to 8 & $2.11 \pm 0.35^{* \star \star}$ & $0.57 \pm 0.26^{*}$ & $0.98 \pm 0.39^{\star *}$ & $0.94 \pm 0.26^{* * *}$ & 7.94 \\
\hline Weeks 8 to 12 & $3.09 \pm 0.48^{* \star *}$ & $1.76 \pm 0.36^{* \star *}$ & $-0.43 \pm 0.53^{\mathrm{ns}}$ & $2.82 \pm 0.36^{* * *}$ & 26.72 \\
\hline Weeks 4 to 12 & $2.60 \pm 0.29^{\star \star \star}$ & $1.17 \pm 0.22^{\star \star *}$ & $0.27 \pm 0.33^{\mathrm{ns}}$ & $1.88 \pm 0.22^{\star \star *}$ & 16.79 \\
\hline \multicolumn{6}{|l|}{ Egg production } \\
\hline ASM, days & $9.62 \pm 1.22^{* \star \star}$ & $5.46 \pm 0.98^{\star \star \star}$ & $-1.29 \pm 1.54^{\mathrm{ns}}$ & $-0.89 \pm 1.96^{\mathrm{ns}}$ & -0.59 \\
\hline P10, days & $2.16 \pm 0.41^{\star \star \star}$ & $0.74 \pm 0.33^{\star}$ & $0.67 \pm 0.52^{\mathrm{ns}}$ & $0.20 \pm 0.66^{\mathrm{ns}}$ & 1.34 \\
\hline EW10, g & $-7.86 \pm 0.56^{* *}$ & $-3.29 \pm 0.46^{* \star *}$ & $-1.29 \pm 0.71^{\mathrm{ns}}$ & $-0.27 \pm 0.91^{n s}$ & -0.58 \\
\hline N90 & $-19.69 \pm 1.38^{\star \star \star}$ & $-9.65 \pm 1.11^{* \star *}$ & $-0.39 \pm 1.74^{\mathrm{ns}}$ & $-1.49 \pm 2.23^{\mathrm{ns}}$ & -2.90 \\
\hline EW90, g & $-9.38 \pm 0.75^{\star \star \star}$ & $-6.06 \pm 0.61^{* * *}$ & $2.73 \pm 0.95^{\star *}$ & $0.32 \pm 1.21^{\mathrm{ns}}$ & 0.62 \\
\hline $\mathrm{EM}, \mathrm{g}$ & $-1534 . \pm 95 .{ }^{* *}$ & $-722 . \pm 77 .{ }^{* \star}$ & $-91 \pm 121^{\mathrm{ns}}$ & $-120 \pm 153.8^{\mathrm{ns}}$ & -4.40 \\
\hline
\end{tabular}

ns: $P>0.05,{ }^{*}: P<0.05,{ }^{*}: P<0.001,{ }^{\star *}: P<0.0001$

ASM: age at sexual mating, P10: the first 10 egg production, MP10: mean of egg production for 10 eggs, EN90: egg number at 90 day, MEN90: mean of egg numbers at 90 days; EM: egg mass

Positive heterosis for BW and DG owing to dominance and epistasis effects contributed to improved growth characteristics (Fairfull \& Gowe, 1990). Therefore, exploiting heterosis in crossing Egyptian local chicken with foreign breeds could increase the growth of chickens being reared in Egypt. The present results agree with those obtained by crossing Fayoumi (local breed) and Rhode Island Red (foreign breed) to produce positive heterosis that ranged from $0.4 \%$ to $7.7 \%$ for bodyweight and $1.3 \%$ to $6.0 \%$ for daily gain (Saleh et al., 2020). Lalev et al. (2014) found that heterosis estimates were positive and highly significant, with percentages from $3.76 \%$ to $22.33 \%$ for bodyweight when two lines of White Plymouth Rock chickens were crossed. Estimates of heterosis for egg production traits were not different from zero. Soliman et al. (2020) likewise did not observe significant heterosis effects for egg production traits.

\section{Conclusion}

The cross between SI and LB strains of chicken was associated with a favourable heterotic effects for producing fast growing and heavy chicks. As an adapted indigenous strain, SI should be considered as a dam line in crossing with LB, which has greater genetic potential for growth. Use of LB as a sire strain in conjunction with SI should increase egg production from the hybrid chickens.

\section{Authors' Contributions}

WSE designed the experiment and collected data. WSH (ORCID ID: 0000-0002-2009-5145) analysed the data and interpreted the results. WSE wrote the draft manuscript and both authors cooperated in revising and finalizing the manuscript.

\section{Conflict of Interest Declaration}

The authors have declared that there are no competing interests.

\section{References}

Abou, EL-Ghar, R.S.H., Ghanem, H.H. \& Aly, O.M., 2010. Genetic improvement of egg production from crossing two developed strains with commercial laying hens. Egypt. Poult. Sci. 30(2), 457-472. 
Amuzu-Aweh, E.N., Bovenhuis, H., De Koning, D.J. \& Bijma, P., 2015. Predicting heterosis for egg production traits in crossbred offspring of individual white Leghorn sires using genome-wide SNP data. Genet. Sel. Evol. 47, 27. DOI: 10.1186/s12711-015-0088-6

Dickerson, G.E., 1993. Evaluation of breeds and crosses of domestic animals. FAO Animal Production and Health Paper 108. Food and Agriculture Organization of the United Nations, Rome.

El-Tahawy, W.S., 2020. Analysis of heterotic components in a cross bred between two Egyptian local chicken strains. Egypt. Poult. Sci. 40(2), 525-535. https://epsj.journals.ekb.eg/article_96405.html

Fairfull, R.W. \& Gowe, R.S., 1990. In: R.D. Crawford (ed.). Poultry breeding and genetics. Elsevier, Amsterdam, The Netherlands.

Fairfull, R.W., Gowe, R.S. \& Nagai, J., 1985. Heterosis in White Leghorn strain crosses. Proc. Brit. Poultry Breeders Roundtable (Edinburgh).

Fairfull, R.W. \& Gowe, R.S., Nagai, J., 1987. Dominance and epistasis in heterosis of White Leghorn strain crosses. Can. J. Animal Sci. 67, 663-680. DOI: 10.4141/CJAS87

Iraqi, M.M., 2008. Estimation of crossbreeding effects for egg production traits in crossbreeding experiment involving two local strains. Egypt. Poult. Sci. 28, 867-882.

Iraqi, M.M, Khalil, M.H. \& EL-Attrouny, M.M., 2012. Estimation of crossbreeding parameters for egg production traits in crossing Golden Montazah with White Leghorn. Livestock Research for Rural Development 24(4). http://www.Irrd.org//rrd24/4/iraq24055.htm

Iraqi, M., Khalil, M.H. \& El-Attrouny, M., 2013. Estimation of crossbreeding components for growth traits in crossing Golden Montazah with White Leghorn chickens. VIth International Conference: Balnimalcon, Tekirdag/Turkiye, 94-504.

Iraqi, M., Afifi, E.A., Abd El-Ghany, A.M. \& Afram, M., 2005. Diallel crossing analysis for livability data involving two standard and two native Egyptian chicken breeds. Livestock Research for Rural Development 17(7). http://www.Irrd.org//rrd17/7/iraq17075.htm

Iraqi, M.M., Afifi, E.A., El-Labban, A.M. \& Afram, M., 2007. Heterotic and genetic components in 4x4 diallel mating experiment for egg production traits in chickens. 4th World Poultry Conference, Sharm El-Sheikh, Egypt.

Iraqi , M., Hanafi, M., El-Moghazy, G., El-Kotait, A. \& Abdel A'AL, M., 2011. Estimation of crossbreeding effects for growth and immunological traits in a crossbreeding experiment involving two local strains of chickens. Livestock Research for Rural Development 23(4). http://www.Irrd.org//rrd23/4/iraq23082.htm

Khalil M.K., Al-Homidan, A.H. \& Hermes, I.H., 2004. Crossbreeding components in age at first egg and egg production for crossing Saudi chickens with White Leghorn. Livestock Research for Rural Development 16(1). http://www.lrrd.org//rrd16/1/khal161.htm

Khalil, M.K., Hermes, I.M. \& AL-Homaidan, A.H., 1999. Estimation of heterotic components for growth and livability traits in a crossbreeding experiment of Saudi chickens with White Leghorn. Egyptian Poult. Sci.19(3), 491-507.

Lalev, M., Mincheva, N., Oblakova, M., Hristakieva, P. \& Ivanova I., 2014. Estimation of heterosis, direct and maternal additive effects from crossbreeding experiment involving two White Plymouth Rock lines of chickens. Biotechnology in Animal Husbandry 30 (1), 103-114. DOI: 10.2298/BAH1401103L

Lamont, S.J. \& Deeb, N., 2001. Genetics of body composition in a novel broiler cross. In: Proceedings XV European Symposium on Quality of Poultry Meat. WPSA Turkish Banch, Ege University, Izmir, Turkey.

Padhi, M.K., 2016. Importance of indigenous breeds of chicken for rural economy and their improvements for higher production performance. Review article. Scientifica volume 2016, Article ID 2604685. 9 pages. http://dx.doi.org/10.1155/2016/2604685

Ramadan, H.A.I., Galal, A., Fathi, M.M., El Fiky, S.A. \& Yakoub, H.A., 2011. Characterization of two Egyptian native chicken breeds using genetic and immunological parameters. Biotechnology in Animal Husbandry 27(1), 1-16. DOI: 10.2298/BAH1101001R

Razuki, W.M. \& AL-Shaheen, S.A., 2011. Use of full diallel cross to estimate crossbreeding effects in laying chickens. International J. Poult. Sci. 10 (3), 197-204. DOI: 10.3923/IJPS.2011.197.204

Saadey, Mekky, S., Galal, A., Zaky, H.I. \& Zein EL-Dein, A., 2008. Diallel crossing analysis for bodyweight and egg production traits of two native Egyptian and two exotic chicken breeds. International J. Poult. Sci. 7(1), 64-71. DOI: 10.3923/IJPS.2008.64.71

Sabri, H.M., Khattab, M.S. \& Abdel-Ghany, A.M., 2000. Genetic analysis for bodyweight traits of a diallel crossing involving Rhode Island Red, White Leghorn, Fayoumi and Dandarawi chickens. Anna. of Agric. Sc., Moshtohor, Vol. 38(4), 1869-1883.

Saleh, M.S., Iraqi, M.M., Khalil, M.H. \& Camarda, A., 2020. Crossbreeding analyses and polymorphic associations of gallinacin genes with growth traits in chickens, Livestock Science 240. https://doi.org/10.1016/j.livsci.2020.104118

Sayed, M.A., Abouelezz, F.M. \& Abdel-Wahab, A.A., 2017. Analysis of sperm motility, velocity and morphometry of three Egyptian indigenous chicken strains. Egypt.Poult. Sci. 37(4): 1173-1185. DOI: 10.21608/epsj.2017.5605

Soliman, M.A., Khalil, M.H., El-Sabrout, K. \& Shebl, M.K., 2020. Crossing effect for improving egg production traits in chickens involving local and commercial strains, Veterinary World 13(3), 407-412. DOI: 10.14202/vetworld.2020.407-412

Soltan, M., Farrag, S., Enab, A., Abou-Elewa, E., El-Safty, S. \& Abu Shady, A., 2018. Sinai and Norfa chicken diversity revealed by microsatellite markers. South African Journal of Animal Science 48(2), 307-315. https://dx.doi.org/10.4314/sajas.v48i2.11

Taha A.E. \& Abd El-Ghany, F.A., 2013. Improving production traits for El-Salam and Mandarah chicken strains by crossing. II-Estimation of crossbreeding effects on egg production and egg quality traits. World Academy of Science, Engineering and Technology Inter. J. Nutr. Food Eng. 7, 10-16. 